\title{
Tako-tsubo cardiomyopathy after a quarrel.
}

\author{
Dong-Mei Jiang ${ }^{1, a}$, Ze-Wei Sunc ${ }^{2, a}$, Jie Han²
}

1. Department of Cardiology, Biomedical research (therapy) center, Sir Run Run Shaw Hospital, College of Medicine, Zhejiang University, Hangzhou, Zhejiang Province, China.

2. Department of Cardiology, The First Affiliated Hospital, College of Medicine, Zhejiang University, Hangzhou, Zhejiang Province, China.

a These authors contributed equally to this work.

\begin{abstract}
:
Objective: To report a case of Tako-tsubo cardiomyopathy in a blind woman.

Case presentation: We report a confirmed case of Tako-tsubo cardiomyopathy in a 55-year-old blind woman with past medical history of ocular trauma. The patient suffered from sudden chest pain after a quarrel. Transthoracic echocardiogram (TTE) showed regional wall motion abnormalities. Coronary angiogram showed no significant coronary stenosis, but ventriculogram demonstrated apical ballooning akinesis and hypercontraction in the basal segments. The follow-up TTE revealed a recovery of systolic function 6 weeks later.

Conclusion: We report a case of Tako-tsubo cardiomyopathy after a quarrel, implicating that severe emotional or physical stress could trigger myocardial stunning.

Keywords: Tako-tsubo cardiomyopathy, ocular trauma, blindness, postmenopause

DOI: http://dx.doi.org/10.4314/ahs.v15i4.39

Cite as: Jiang D-M, Sun Z-W, Han J. Tako-tsubo cardiomyopatby after a quarrel. Afri Health Sci. 2015;15(4):1349-53. bttp://dx.doi. org/10.4314/abs.v15i4.39
\end{abstract}

\section{Introduction}

Tako-tsubo cardiomyopathy, or broken heart syndrome, is a novel and enigmatic cardiac syndromes that mimic acute myocardial infarction ${ }^{1}$. The disorder is more commonly seen in postmenopausal women. Usually there is a history of recent excessive emotional or physical stress $^{2,3}$, implicating an abnormal cardiac response to increased catecholamines. Although death has been reported in the acute phase ${ }^{4}$, supportive treatment usually leads to good long-term prognosis with full recovery of left ventricular function ${ }^{5}$.

\footnotetext{
Corresponding author:

Jie Han,

Institute of Cardiology,

The First Affiliated Hospital,

College of Medicine, Zhejiang University,

No.79 Qingchun Road, Hangzhou 310003, China.

E-mail: hanjiephd@hotmail.com.

Tel: +86571 85519933;

Fax:+8657187236569
}

It was first recognized in Japan by Satoh ${ }^{6}$ and Dote ${ }^{7}$, and tako-tsubo refers to the end-systolic appearance of the left ventricle on ventriculography and its resemblance to the round bottomed, narrow necked Japanese fishing pots used to trap octopus. The cardiomyopathy is characterized by (1) sudden onset of chest pain or shortness of breath; (2) reversible akinesis around the left ventricle (LV) apex and hyperkinesis around the LV outflow; (3) electrocardiographic (ECG) changes (ST segment elevation); (4) Mild to moderate elevation myocardial enzymatic release; and (5) No evidence of obstructive coronary artery disease on cardiac catheterization ${ }^{8}$.

The pathophysiological mechanism associated with Tako-tsubo cardiomyopathy is higher prevalence in postmenopausal women remains unclear, although broadly speculated on. In the present report, we describe a case of Tako-tsubo cardiomyopathy after a quarrel in a blind postmenopausal woman.

\section{Case presentation}

A 55-year-old postmenopausal woman was admitted to our hospital with severe non-radiating chest pain, and 2 hours prior to admission she had experienced an impetuous quarrel. She felt better with buccal nitroglycerin 
approximately an hour later. She had a significant past medical history of severe ocular trauma, which resulted in her left monocular blindness 20 years ago. She was a non-smoker with no history of hypertension or diabetes mellitus.

\section{Physical examination:}

Vital signs: T $37.2^{\circ} \mathrm{c}$ P 60/min, R 20/min, BP160/90m$\mathrm{mHg}$.

Lungs: Respiratory movement was bilaterally symmetric with the frequency of $20 / \mathrm{min}$. Thoracic expansion and tactile fremitus were symmetric bilaterally. No pleural friction fremitus. Resonance was heard during percussion. No abnormal breath sound was heard. No wheezes. No rales.

Heart: No bulge and no abnormal impulse or thrills in precordial area. The point of maximum impulse was in $5^{\text {th }}$ left intercostal space inside of the mid clavicular line and not diffuse. No pericardial friction sound. Border of the heart was normal. Heart sounds were strong and no splitting. Rate $60 / \mathrm{min}$. Cardiac rhythm was regular. No pathological murmurs.

Abdomen: Flat and soft moving with respiration symmetrically. No bulge or depression. No abdominal wall varicosis. There was no tenderness and rebound tenderness on abdomen or renal region. No palpable masses or organomegaly. Murphy's sign was negative. No shifting dullness. Liver was tipped $1.5 \mathrm{~cm}$ under the right costal margin. No costovertebral angle tenderness.

ECG revealed $1.5 \mathrm{~mm}$ ST segment elevation in V1-V2 leads, diffuse T-wave inversion in V3-V9 leads and QT prolongation (Figure.1 A).

Cardiac enzymes were initially elevated with peak Troponin I (TNI) to $2.953 \mathrm{ng} / \mathrm{ml}$ (normal range 0.000 $0.022 \mathrm{ng} / \mathrm{ml})$, lactate dehydrogenase $(\mathrm{LDH})$ to 313 IU/L (normal range 89-240 IU/L), creatine kinase (CK) to $270 \mathrm{IU} / \mathrm{L}$ (normal range 26-198 IU/L) and CK-MB sub- fraction (CK-MB) of $31 \mathrm{IU} / \mathrm{L}$ (normal range $0-24 \mathrm{IU} / \mathrm{L})$, while the white blood cell count and $\mathrm{C}$ reactive protein (CRP) level were not elevated. She was commenced on aspirin, clopidogrel, low molecular weight heparin, beta-blocker, and ACE-inhibition. A transthoracic echocardiogram demonstrated severely impaired LV systolic function with akinesia of all apical segments, with normal basal contraction and a $53 \%$ left ventricle ejection fraction (LVEF).

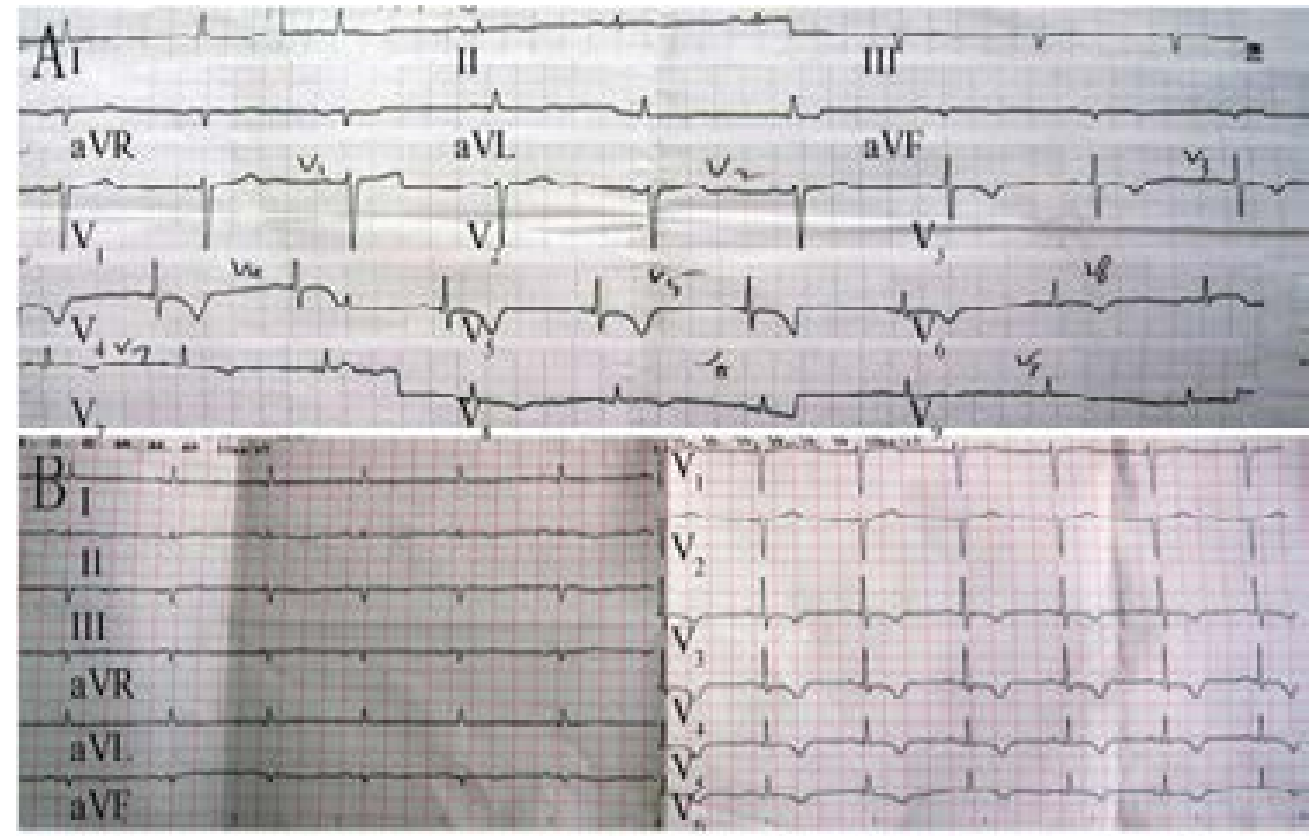

Figure I. (A) ST-segnent elevation in the VI-V2 leads followed by diffuse

T-wave inversion in V3-V9 leads with OT prolongation. (B) T-wave still inversion in V3-V6 leads with QT prolongation 12 days later. 
She was transferred to the catheterization laboratory for coronary angiography, an about $20 \%$ stenosis in proximal-mid left anterior descending artery (LAD) was found, the left circumflex and right coronary artery were normal (Figure.2 AB). Left ventriculography disclosed apical ballooning akinesis with concomitant compensatory basal hyperkinesis (Figure.2 CD).

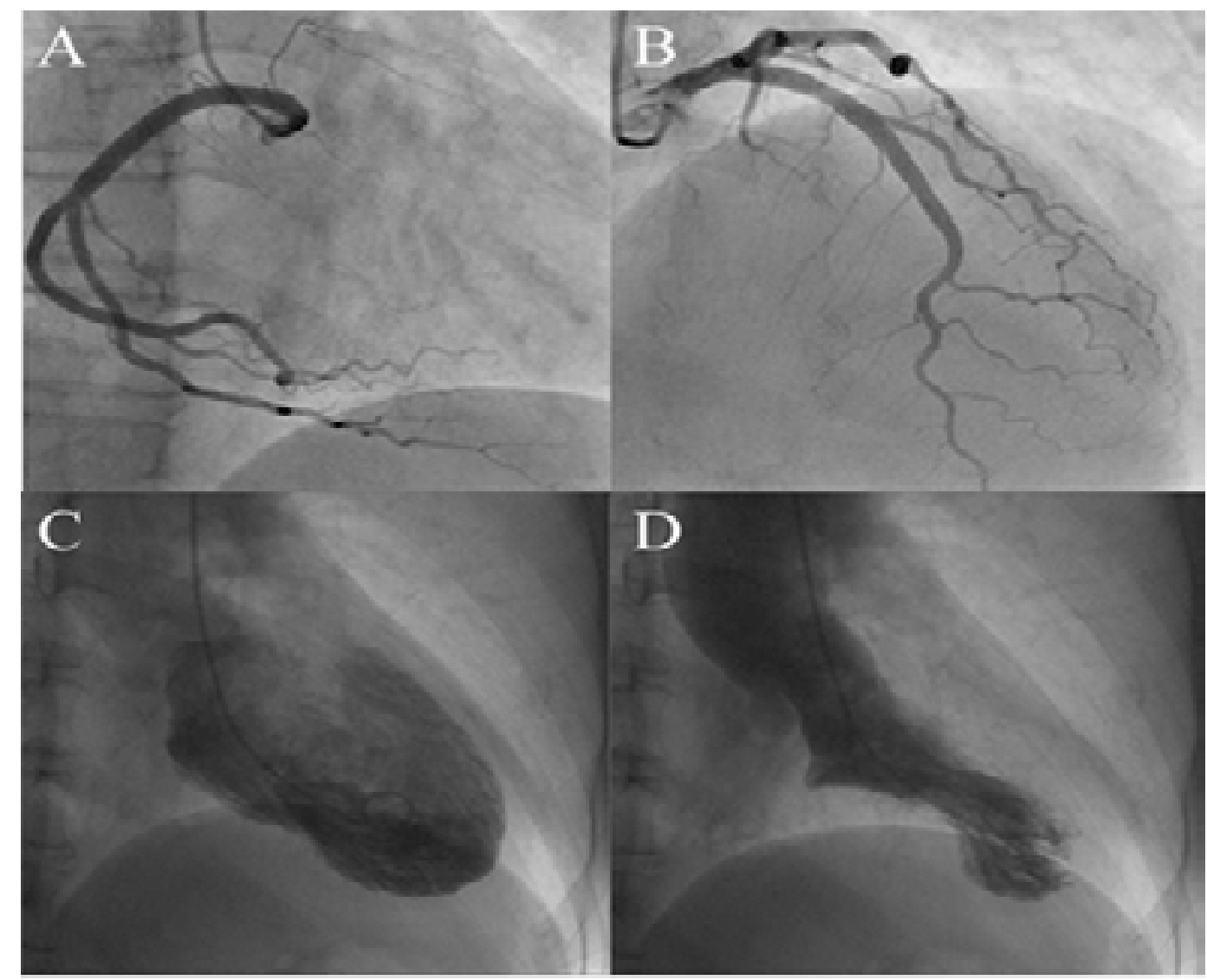

\begin{abstract}
Figure 2. (AB) In coronary angiograe $20 \%$ stenosis in proximal-mid left anterior descending cononary artery (LAD), other coronary arteries were normal. (CD) The left ventriculogram illustrating hyperdynamic basal contraction but akinesis of the apical segments in systole.
\end{abstract}

ECG showed no significant alternation compared to the initial 12 days later (Figure.1 B). Laboratory examination revealed normal cardiac enzymes including TNI (0.01 ng/ml), LDH (233 IU/L), CK (64 IU/L), CKMB (19 IU/L).

The patient's condition improved and she was discharged from the hospital after 7 days. The follow-up TTE (6 weeks later) showed complete regression of regional wall motion abnormalities with an increase of $\operatorname{LVEF}(71.6 \%)$.

\section{Discussion}

Our patient presented with typical clinical features of Tako-tsubo cardiomyopathy, sudden onset chest pain induced by emotional stress. Our patient also had an ECG feature of ST segment elevation and T-wave abnormalities in the precordial leads, mildly elevated cardiac biomarkers, a characteristic octopus pot morphology on echocardiogram and left ventriculogram. Moreover, the left ventricular dysfunction completely resolved weeks after event. 
Severe reversible left ventricular dysfunction (myocardial stunning) in patients without marked coronary disease is thought to be caused by excessive exposure to catecholamines mediated by exaggerated sympathetic stimulation after an episode of emotional or physical distress $^{1-4}$. Our patient had Tako-tsubo cardiomyopathy induced by emotional stress in post menopause. Previous reports show that most patients who have Tako-tsubo cardiomyopathy are postmenopausal women ${ }^{9}$. Gianni et al. ${ }^{10}$ reviewed studies and found that of 286 patients with the syndrome, 254 (89\%) were female. The mean age of the patients was 68.5 years.

The reason for the much more common occurrence in postmenopausal women is unclear. Does a difference exist between the genders in the psychological response to stress that triggers an abnormal physiological change? Is the cardiovascular system of females physiologically or anatomically more sensitive than that of men to catecholamines? Several explanations have been proposed. Sex hormones may influence the sympathetic nervous system and may affect coronary vasoreactivity or the tendency to spasm ${ }^{11,12}$, but sex-related differences in catecholamine metabolism and responsiveness are complex and remain poorly understood. Women appear also to further increase vulnerability to sympathetically mediated myocardial stunning ${ }^{13}$, and postmenopausal alteration of endothelial function in response to reduced oestrogen levels has been advocated as a possible alternative explanation ${ }^{14}$. Ueyama et al. ${ }^{15}$ suggested that increase of serum estradiol levels can diminish the pathological changes in the heart with protective effect against Tako-tsubo.

\section{Conclusion}

Tako-tsubo cardiomyopathy is an increasingly recognized condition. We present a case of Tako-tsubo cardiomyopathy after a quarrel in a blind postmenopausal woman, significantly supporting the recognition that postmenopausal females appear to be more vulnerable to myocardial stunning by emotional or physical stress.

\section{Conflicts of interest statement}

The authors have no conflict of interest to declare.

\section{Funding:}

No specific funding was received for the study.

\section{References}

1. Kurisu S, Sato H, Kawagoe T, Ishihara M, Shimatani $\mathrm{Y}$ et al. Tako-tsubo-like left ventricular dysfunction with ST-segment elevation: a novel cardiac syndrome mimicking acute myocardial infarction. Am Heart J. 2002;143(3):448 PubMed -455.

2. Wittstein IS, Thiemann DR, Lima JA et al. Neurohumoral features of myocardial stunning due to sudden emotional stress. N Engl J Med. 2005;352(6):539 PubMed -548 .

3. Mizutani K, Okada M. A case of intraoperative repeated coronary artery spasm with ST-segment depression: Masui. 2002;51(10):1114 PubMed -1116.

4. Akashi YJ, Tejima T, Sakurada H et al. Left ventricular rupture associated with Takotsubo cardiomyopathy. Mayo Clin Proc. 2004;79(6):821-824.

5. Kyuma M, Tsuchihashi K, Shinshi Y et al. Effect of intravenous propranolol on left ventricular apical ballooning without coronary artery stenosis (ampulla cardiomyopathy): three cases. Circ J. 2002;66(12):11811184.

6. Satoh H, Tateishi H, Uchida T, Ishihara M. Takotsubo-type cardiomyopathy due to multivessel spasm. In Clinical aspect of myocardial injury: from ischemia to heart failure, p. 56-64 (Ed. Kodama K, Haze K, Hon M). Tokyo: Kagakuhyouronsya Co, 1990.

7. Dote K, Sato H, Tateishi H, Uchida T, Ishihara M. Myocardial stunning due to simultaneous multivessel coronary spasms: a review of 5 cases. J Cardiol. 1991;21(2):203-214.

8. Derrick D. The"broken heart syndrome": understanding Takotsubo cardiomyopathy. Crit Care Nurse. 2009;29(1):49-57, 58.

9. Donohue D, Movahed MR. Clinical characteristics, demographics and prognosis of transient left ventricular apical ballooning syndrome. Heart Fail Rev. 2005;10(4):311-316.

10. Gianni M, Dentali F, Grandi AM, Sumner G, Hiralal R, Lonn E. Apical ballooning syndrome or takotsubo cardiomyopathy: a systematic review. Eur Heart J. 2006;27(13):1523-1529.

11. Hinojosa-Laborde C, Chapa I, Lange D, Haywood JR. Gender differences in sympathetic nervous system regulation. Clin Exp Pharmacol Physiol. 1999;26(2):122126.

12. Sader MA, Celermajer DS. Endothelial function, vascular reactivity and gender differences in the cardiovascular system. Cardiovasc Res. 2002;53(3):597 PubMed $-604$. 
13. Lambert G, Naredi S, Eden E, Rydenhag B, Friberg P. Monoamine metabolism and sympathetic nervous activation following subarachnoid haemorrhage: influence of gender and hydrocephalus. Brain Res Bull. 2002;58(1):77 PubMed -82.

14. Taddei S, Virdis A, Ghiadoni L et al. Menopause is associated with endothelial dysfunction in women. $\mathrm{Hy}$ pertension. 1996;28(4):576-582.

15. Ueyama T, Hano T, Kasamatsu K, Yamamoto K, Tsuruo Y, Nishio I. Estrogen attenuates the emotional stress-induced cardiac responses in the animal model of Tako-tsubo (Ampulla) cardiomyopathy. J Cardiovasc Pharmacol. 2003;42 Suppl 1:S117-S119. 